\title{
A Qualitative Assessment of Unemployment and Psychology Fresh Graduates' Job Expectation and Preference
}

\author{
Shimelis Keno Tulu \\ Department of Psychology, College of Education and Behavioral Science, Arsi University, Asella, Ethiopia
}

Email address:

shimeliskeno8@gmail.com,shimelis.keno@yahoo.com

\section{To cite this article:}

Shimelis Keno Tulu. A Qualitative Assessment of Unemployment and Psychology Fresh Graduates' Job Expectation and Preference. Psychology and Behavioral Sciences. Vol. 6, No. 2, 2017, pp. 21-29. doi: 10.11648/j.pbs.20170602.12

Received: March 28, 2017; Accepted: April 8, 2017; Published: May 9, 2017

\begin{abstract}
This study is conducted to assess the fresh graduate of psychology students' job expectation and preference in relation to the existing high unemployment rate. A simple qualitative research method with a cross sectional research design is employed in order to collect detailed and comprehensive information from the participants. The total number of population for this study is all 87 psychology $3^{\text {rd }}$ year students. Using academic achievement, place of residence and sex as an inclusion criterion, 32 participants (of which 16 were female and the rest 16 were male) were purposefully selected. To collect the desired information, semi-structured interview and Focus Group Discussion (FGD) were employed. The result of the study revealed that, majority of psychology fresh graduates expect and prefer to be employed in their field of specialization. It is also found that, fresh psychology graduates' job expectation and preference are affected by their sex, in which female fresh graduates are found to have low expectation and preference. It was also found that, academic achievement and residence have affected fresh psychology graduates' job expectation and preference. Majority of fresh psychology graduates with high academic achievement expect and prefer to be employed in their field of specialization with the highest salary, unlike those with relatively lower academic achievement. With some exceptions due to sex and academic achievement, majority of psychology fresh graduates' job expectation and preference are affected by their residence. That is, fresh psychology graduates from rural area are found to have less expectation and preference of being employed in their field of specialization.
\end{abstract}

Keywords: Fresh-Graduate, Unemployment, Job Expectation \& Preference, Academic Achievement

\section{Introduction}

Since it was coined, different scholars in different fields defined unemployment differently. But, the best definition is the one defined by International Labor Organization, which states that, "unemployment is happen when a person who is currently seeking for work stay without work, and seeking for work [1]. Unemployment can also be defined as the state in which people who can work are without jobs and are seeking for pay or profit [2].

The problem of unemployment is already become the serious challenge and headache for many countries of the world. As reported by International Labor Organization (ILO), globally, the number of unemployed youth is already reached 88 million. More than one-third of the world young population are either searching for job or working but still leading life with below poverty line, gaining below 2 USD per day [1].

Although it is a world-wide problem, unemployment is mostly intense in developing countries like Ethiopia [2]. In sub-Saharan Africa; youth unemployment is very high and getting worse as the number of young people who are seeking job is rapidly increasing. It is project that, young people looking for job in sub Saharan Africa will increase by $28 \%$ in the coming 15 years [3].

Ethiopia is one of the countries in Sub-Saharan Africa that is on track to meet most of the Millennium Development Goals, including development in the educational sector [3]. Currently Ethiopia is achieving significant progress in educational sector; increased access at all levels of the education system in line with a sharp increase in the number of teachers, schools and Universities. Despite remarkable 
development in most sectors, like most developing countries, there is unemployment problem in Ethiopia [4]. Following rapid expansion in higher educational institution, currently large numbers of fresh graduates are graduating from about 33 governmental Universities; of which most of them are facing difficulties of being employed. Ethiopian economic development is unable to hold labor market and unemployment is continues to be one of the most serious problems for most fresh graduates [5]. If every fresh university graduates are asked to list their top five serious problems, one must be unemployment.

As far as age is considered, unemployment is a serious problem of youth than others segment of population. E.g., the unemployment rate in 2005 E.C. was $29 \%$ as stated by [3]. The large portion of this unemployment rate is attributed to fresh university graduates. It is common to see fresh graduates who have been searching for job for the last two or three year but unable to find.

Due to Unemployment, many educated young Ethiopians are illegally migrating to Europe and Arab countries. Unfortunately, most migrants are facing even serious health problem, dying in container and killed by robbers. Majority of home servant in Arab countries are young Ethiopians female who fail to get job; taking migration as their last option. They are underpaid, forced to over work, sexually abused and in most case, they are refused to get their salary.

With the mentality of expecting being employed by government in the society and at individual level on one hand and the high rate of unemployment on the other hand, it is reasonable to question what type of job expectation and preference fresh-graduates will have. Therefore, the purpose of this study is to investigate Psychology fresh-graduates' job expectation and preference in line with the existing unemployment problem in Ethiopia.

\subsection{The Concept of Unemployment}

The concept of unemployment is always one of the most significant social issues. The fundamental reason that makes the concept of unemployment so important is that, it does not only affect the economic development of society, but also the stability of the society. Employment determines how a society is like, how it is going to develop and it affects how people define themselves [4]. Everybody can imagine what happen if massive numbers of people are jobless and hence has nothing to earn, eat and sustain life. Unless the problem of unemployment is managed properly; the social, economic and political consequences it causes is very disastrous at all individual, family and society levels [6].

\subsection{Major Causes of Unemployment for Fresh University Graduates}

There are many reasons that result in the problem of unemployment. But, Economists explain that, most of the time, high unemployment rate is an indication of the failure of country's economy to accommodate and use labor resource effectively [2]. Scholars agree that, the same logic holds true when it comes to the problem of unemployment for young Ethiopians fresh University graduates. Basically, the following are major causes of unemployment for fresh university graduates in Ethiopia:

\subsubsection{Lack of Job Searching Skills and Experience}

Job searching skills are techniques that are necessary to find a competent job; based on our interest, potential and the existing real situation. We are living in a highly competitive world, where job searching is the most challenging task for most individuals, mainly for fresh graduates [7]. When we think of searching jobs, there are so many questions that repeatedly come to our mind and disturb us. E.g. where and how to find fitting job? How to stand first in getting job? How to prepare an eye-catching $\mathrm{CV}$ and how to make preparation for interview? The answer for these questions actually comes from utilizing appropriate mechanisms of searching job [8].

Career psychologists suggest that, individuals who search job need to have knowledge about different job searching techniques. Searching a job without knowledge of how to search a job is common problem for most young fresh graduates [9]. When it comes to the Ethiopian context, most fresh-graduates have no know-how of searching a type of job that fits their skills, knowledge, interest, potential and psychological readiness. Being graduated from university with certain field of specialization does not give guarantee of getting job unless the graduates also have good job searching skills, using available options. There is a trend that fresh graduates expect the job to come to them, rather than they go to the right place where job is available.

\subsubsection{Lack of Practical Work Experiences}

Study shows that, fresh graduates are three times more likely to be unemployed when compared to experienced adults. The reason is that, unlike fresh graduates, adults have more years of work experience, have better linkage to different employing organizations, have better job-searching skills and even more favored by employing organizations [3]. Currently, labor market is becoming more competitive from time to time and only fresh graduates with high performance get the small share of employment left from those who have more practical work experiences [10]. Normally, employers expect good experiences, high quality skills and knowledge, from fresh graduates, while fresh graduates may not satisfy all these expectations. Hence, to fill such gap, vacancies that are posted online, in newspaper and released on radio and television ignore fresh graduates who have zero level of experience. For most organizations, it is more important to employ individuals with more work experience even with lower academic qualification [11].

With fresh graduates' low level of experience and skills, employing companies select only graduates with high performance and good experience. E.g., the findings of one survey show that, $97 \%$ of the respondents from different employing companies considered work experience as a preferred quality during their job assessments [10]. This automatically pushes fresh graduates out of the game and 
they can lose hope and lack commitment to search job repeatedly.

\subsubsection{Mismatch between Expectation and Reality on the Ground}

Research findings show that, after graduation, most graduates, especially those who are good achievers expect job [11]. Fresh graduates' level of self-efficacy which is the belief that one can achieve the desired results also matters their level of expectation [12]. When it comes to the Ethiopian context, there is a similar trend. Before two decades, when there were no more than 3 or 4 Universities in Ethiopian, almost all graduates were soon employed; as there was small number of graduates with equal or even more job opportunities [6].

There is still such mentality both with the graduates and their families; where the reality on the ground is dramatically changing and now it is hard to be employed. With low level of job creating interest and ability, most fresh graduates have the mentality to be employed after graduation [13]. Such hope leads them to intolerance and inability to overcome challenges [14].

\subsubsection{Discrepancy between Economic Power and Number of Graduates}

In Ethiopia, for the last 15 years, there has been a rapid expansion of Universities; resulting in large number of graduates with low quality [3]. Currently, while there are about 50, 000 degree graduates each year from Universities yearly, the economic development of Ethiopia is still far to go to accommodate these graduates. For most developing countries like Ethiopia, weak economic performance is a major problem and such low job opportunity is the result of low economic growth [13].

Compared to the huge number of fresh graduates searching for job, there are limited number of government sectors, NGOs and other employing sectors that can employ insignificant number of fresh graduates [13]. Majority of graduates remain unemployed each year, where universities are continue graduating more number of fresh graduates each year; creating cumulative effects to the already existing unemployment problem.

\subsubsection{Low Quality Graduates Who Lack Proper Skills, Knowledge and Practice}

Similar to other Sub-Saharan African countries, one major cause of unemployment in Ethiopia is fresh graduates' lack of desired theoretical knowledge, positive attitude and practical experience [15]. Education in Ethiopia is not well-developed yet and it lacks the capacity to produce qualified graduates; as the focus is given to mass education at the expense of quality graduates. There is concern regarding Ethiopian educational policy; as graduates are not satisfying the requirements of labor market [3]. It is not secret that the current educational policy of Ethiopia in general and that of higher educational institutions in particular is highly criticized for their large number of graduates with low quality, compared to the expected universal standard.
While employers expect and look for those graduates with good academic achievement that matches with other related skills, such as flexibility, interpersonal skills, communication skills and problem solving skills; fresh graduates in most case lack such qualities [16]. The current trend of Ethiopian higher education has double-faced; one face is the positive side; which is characterized by fast growing in terms of both the number of universities and number of young students attending university. The other face is the negative side that characterized by mass education with low quality graduates [17].

Graduates are more likely to be employed by industries when they possess a good sense of achievement which is characterized by skills, knowledge and other related qualities which benefit the industries in particular and the community at large [16]. But, scholars agree that, Ethiopian educational policy is not designed in the manner it can produce graduates who can satisfy the need of employers, or else have jobcreating mentality [17].

\subsection{Fresh Graduates'Job Expectation and Preference in Relation to Unemployment}

Whether being employed by others or self-employed, everybody expect to have certain good job and prefer good income or salary. But, with a very high number of fresh gradates interning the market, employing organizations are still searching for who is best [16]. The expectation regarding their future job among fresh graduates is expected to be high due to different personal, family and social reasons [10]. When there is high unemployment problem, like what is happing now in Ethiopia, obviously, there is a tendency to anticipate where to be employed, what to work and how to get good salary. Because, fresh graduates need to have job with better salary as they are expected to compensate their poor family who educated them with some future hope and expectations to be benefited from their children in return [16].

\subsection{Gender Difference in Job Expectation and Preference}

In Ethiopia, while unemployment is common problem, the rate of unemployment is higher for female than male, especially in rural area. Not only that, male and female fresh graduates have different expectations and preferences about their future job. Research findings suggest that, male and female tend to be different on their job expectation, preference and even on how to solve problems [18]. Female tend to expect smaller pay for own work than men. Not only expectations, female also tend to expect and prefer simple and easily available job when compared to male [19]. Different factors such as; cultural, traditional and social values that have shaped female's thinking are believed to contribute for female' slow-self-esteem about their jobs expectation and preference. Like male, women expect and prefer to work to get money, but they generally consider it as a secondary duty to their domestic responsibilities [20].

Though things are getting better, in Ethiopia there is still 
gender gap as far as employment, job expectation and preference are concerned. The attitude of preferring male over female for better and difficult job during employment is still common. Even, with the same academic achievement and experience, majority of organizations give priority for male [21]. Beside the existing high unemployment rate, wrong attitude towards female result in female's high unemployment rate. For example; one survey conducted in 2005 E.C. revealed that, the rate of unemployment is about $9 \%$ for female and $4 \%$ for male, showing higher rate of female unemployment [22]. Likewise, urban female unemployment rate is $27 \%$ while it is only $13 \%$ for male, which shows that young female graduates are facing higher unemployment problem [3].

In most cultures, the society at large and the employing organization in particular have wrong belief that, male perform better than female in the real working setting. The societies' belief that female have low self-esteem and less confident; hence, less productive than male is not changed yet. There are female bosses who prefer to employ male than female for their organization, proving that, female themselves underrate other female's ability to perform. Such societal and organizational belief and expectation lead male graduates to expect and prefer better or even difficult job with highest salary, while it is negatively affecting the expectation and preference of female graduates. Also, in the process of employment, there are biases, harassment and sexual abuse that affect female graduates than male. Even though it is hard to get official data, it is common to hear female criticizing their employers for sexual abuse and harassment.

\subsection{Job Expectation and Preference in Relation to Academic Achievement}

Many factors such as family related factors, academic related factors, and job commitment create stressors for university students [23] For example, for fresh graduates with high academic achievement expect and prefer good job with high salary, unlike those who have low academic achievement [16]. Similarly, in Ethiopia, most employing organization, including universities uses academic achievement or Cumulative Grade Point Average (CGPA) as the main criteria while recruiting new graduates. E.g.; the minimum Cumulative Grade point Average for fresh graduate to be employed in Ethiopian University as Graduate Assistance One (GA-I) is CGPA of greater than or equal to 2.75 [21]. This shows that, employing organizations belief that, academic achievement predicts the skills and knowledge of graduates. Hence, fresh graduates with high academic success normally expect that they can get good job. Also, graduates with low academic achievement may belief that it is hard for them to compete with high achievers and get good job.

\subsection{Graduates' Residence in Relation to Job Expectation and Preference}

In our today's world, where the problem of unemployment is so serious and finding job is too difficult, fresh-graduates expected to actively and consistently look for vacancy and search for job [7]. But, in Ethiopia, where graduates have limited job-searching skills, the graduates' residence creates another burden. Most vacancies are written on newspaper, posted online, aired on radio and television and all these are very limited to urban areas where electric power and internet connections are available. Therefore, it is too difficult to follow up different vacancies for those fresh-graduates living in rural area [22].

Additionally, the high cost of transportation from rural to urban and hotel cost are another headache for fresh graduates. Most of them are from remote area and poor family; hence cannot afford the cost of frequent transportation to different towns and properly follow up vacancies.

\section{Statements of the Problem}

In Ethiopia, massive numbers of students are graduated from different universities each year. So, it is common to observe unemployed people after graduating from higher institutions. Due to the problem of unemployment, fresh graduates are forced to involve in different tasks out of their specialization and even it is common to observe professionals when they are migrating illegally living their country after graduation from universities. The government of Ethiopia prepares small scale business like, cobblestone works, woodwork and metal works, and animal breading. But, the fresh graduates' attitude toward such jobs is very poor, as do not prefer to engage out of their profession. Parents do not want to see their adolescents working in such tasks, being graduated from University and holding degree. Such societal and parental expectation affects the expectation and preference of fresh graduates.

While the problem of fresh graduates' unemployment is becoming very serious in Ethiopian, their job expectation and preference are not fit with this existing reality. Unfortunately, to the best of the researcher's knowledge, there is no research conducted in this area previously.

Therefore, the rationale to conduct this study is to investigate psychology fresh graduates' job expectation and preference as well as their psychological readiness to cope up with the existing unemployment problem.

\section{Research Questions}

This study is meant to answer the following basic research questions:

a. What expectation and preference do psychology fresh graduates have about their future job?

b. Do female and male fresh graduates have different job expectation and preference?

c. Does academic achievement (CGPA) of fresh graduates affects their job expectation and preference?

d. Does the place of their residences affect freshgraduates' job expectation and preference? 


\section{Objectives}

\subsection{General Objective}

The general objective of the study is to investigate psychology fresh-graduates' job expectation and preference.

\subsection{Specific Objectives}

a. To identify psychology fresh graduates' job expectation and preference.

b. To assess gender difference in psychology freshgraduates' job expectation and preference.

c. To examine the influence of academic achievement on psychology fresh graduates' job expectation and preference.

d. To investigate the influence of residence on psychology fresh-graduates' job expectation and preference.

\section{Methodology}

\subsection{Research Design}

The qualitative research method with cross sectional research design is employed to collect detail and broad information from participants. Participants are selected from different socio-economic backgrounds, sex, residence and academic achievement. The main reason why qualitative method is employed in this study is that, it is very essential to assess the detail and in-depth information from participants [24]. Participants have better freedom in expressing their career expectations and preferences when they are asked using open ended questions through semi-structured interview and Focus Group Discussion in qualitative research [25].

\subsection{Research Site}

The study was conducted in Mekelle University, College of Social Sciences and Languages, Psychology Department $3^{\text {rd }}$ year students. Under the College of Social Sciences and Languages, there are different departments but the researcher purposively selected Psychology $3^{\text {rd }}$ year students as participants of the study. The reason is that, psychology students have assumed to have better understanding on how to overcome the problem of unemployment, how to make good decision about their career and how to balance their expectation with reality.

\subsection{Population and Samples of the Study}

The total number of population for this study was all 87 psychology Fresh graduates of 2007 E.C. From this population, the researcher has purposively selected 32 participants who have different (academic achievement, sex and residence). These 32 students are the mixture of low, medium and high level of academic achievers. The standard for categorizing students in to low, medium and high academic achievement is based on their 5 semesters' cumulative grade point average (CGPA). The participants were also from rural and urban area. In addition, to collect diversified information from the diversified population, the researcher intentionally selected 16 male students and 16 female students as participants of the study.

\subsection{Instruments of Data Collection}

Two instruments of data collection, namely semistructured interview and Focus Group Discussion (FGD) were employed to collect wide-range and detail information on psychology fresh graduates' job expectations, and preferences. To collect accurate and desired data, semistructured interview questions were developed, and detail interviews were conducted with all participants. Also, for the sake of triangulating data, the researcher also conducted hot and interesting focus group discussion with study participants. The FGD was helped the researcher to understand the feeling of all participants in relation to their job expectations and preferences.

\subsection{Data Collection Procedures}

Having developed the instruments of data collection and point of discussions, 30 voluntary fresh graduates were purposively selected. Then, researcher has conducted semistructured interview with each participant and finally Focused Group Discussion was conducted in a round table with all participants. This kind of information gathering system has helped the researcher to get the whole picture of participants. Having collected the desired data from the participants, the researcher put the information in category, to make data analysis easy and smooth.

\subsection{Inclusion Criterion}

In this study, the inclusion criterions used to select participants were; fresh graduates' cumulative grade point average (CGPA), sex and place of residence.

\subsection{Ethical Considerations}

While conducting this study, due consideration was given for basic ethical issues. First, participants' informed consent was obtained before data collection was started. They were informed (in the language they understand) about the objectives of the study, the potential benefits they may get from the study and the possible discomfort they might experiences during their participation in the study. Moreover; participants were informed about their rights and duties during the interview sessions and Focus Group Discussion. They also informed that, they can stop the interview and discussion sessions when it goes in a way that exposes their privacy.

\subsection{Data Analysis and Interpretation}

Qualitative data were thematically analyzed; making groups for similar answers from different participants. That is; similar answers of the participants clearly explained in a paragraph in narrative form. Data collected from diversified 
population used to compare with each participant's demographic information like sex, residence and cumulative grade point average.

\section{Results and Discussions}

\subsection{Participants'Socio-demographic Information}

Table 1. The Socio-Demographic Composition of the Participants.

\begin{tabular}{lllll}
\hline Variables & Categories & No & \% \\
\hline \multirow{2}{*}{ Sex } & Male & & 16 & 50 \\
& Female & & 16 & 50 \\
Residence & Rural & & 16 & 50 \\
& Urban & & 16 & 50 \\
\multirow{2}{*}{ Grade } & $2.00-2.74$ & Distinctions & 8 & 25 \\
Distinction & $2.75-3.24$ & Low distinction & & \\
& $3.25-3.74$ & High distinction & 8 & 25 \\
& $3.75-4.00$ & Very high distinction & 8 & 25 \\
\hline
\end{tabular}

The above table 1 shows participants' the sociodemographic composition in terms of sex, residence and academic achievement. These variables are assumed to have their own influence on the outcome of the research; hence clearly stated in the results gained through interview and Focus Group Discussion below:

\subsection{Psychology Fresh Graduates'Job Expectation and Preference}

With some variations due to their sex, academic achievement, residences and personal attitude; majority of Psychology fresh graduates have similar job expectation and preference. That is, majority of them (72\%) expect and prefer to be employed in either government or NGOs with their profession and high salary, after their graduation. For Example; when asked about their job expectation and preference, majority of them that is $(68.75 \%)$ were answered as follows:

"We have spent 3 years in university. We have come across lots of challenges and difficulties. We suffered a lot to successfully complete our education. Now we expect to be employed in different organizations with better salary. We also deserve or prefer to have excellent job of our profession and enjoy good salary. Who learns 3 years in campus to back to our families' home or else to create our own simple jobs that do not require joining university?"

\subsection{Gender Difference in Job Expectation and Preference}

As of the findings of this study, in relation to job expectation and preference, male and female fresh graduates are different. While male fresh graduates tend to expect difficult and challenging jobs with highest salary and prefer job in their field of specialization, female fresh graduates, tend to expect less challenging job with moderate or less salary and prefer simple jobs regardless of salary. While male want most difficult jobs with highest salary partly due to the reason that it offers them social respect and value, female want socially acceptable jobs. Female's job expectation and preference is influenced by factors such as culture, traditions and social value.

What is odd to the findings of this study is the response of one female fresh graduate from rural area with academic achievement of great distinction. When asked the question: Do you expect and prefer less challenging jobs because you are female? She stated that:

"As a female, I personally belief that we are equal, even can be better than male in some aspects. It is the culture in which we live that has been affecting us negatively. In my case, I want to have challenging and difficult jobs like male. I want to see the challenges practically."

\subsection{Academic Achievement in Relation to Job Expectation and Preference}

In this study, it is found that, regardless of their residence and academic achievement, majority of male fresh graduates expect good job with high salary. Male fresh graduates with very high academic achievement have the highest expectation and preference. E.g. when asked the question: As a fresh graduate with very high academic achievement, do you think that you will get job? One male fresh graduate with very great distinction academic achievement stated that:

"Of course; I am about to be graduated from psychology department with highest achievement. I am also good in communication skills and I am sociable. For the last three years, I have suffered a lot, I did all what is expected of me and now it is time to expect good job and I really give priority to job that helps me to earn highest salary. Good job with high salary helps me to compensate my poor family. Not only me, everybody in my family are also expecting me to get job and make them happy. After all, who should expect and prefer a good job, if not me?"

On the other hand, there are high achievers male fresh graduates with the same academic achievement, but from different residence, who have different job expectation and preference. E.g., let compare the following responses obtained from two male fresh graduates. When asked: What type of job you expect and prefer as male fresh graduate with good academic achievement?

a. Male Psychology fresh graduate from rural area stated that:

"I live in rural area. Do not forget that this is Ethiopia, where there are plenty of social, cultural and economic burdens. I am high achiever. But, I think it could be too difficult for me to be employed as having good grade is not enough. I am from poor family; I cannot afford travelling to different cities and check for job vacancy. I have to correct my expectation with reality."

b. Male Psychology fresh graduate from urban area responded that:

"Although the competition will be very difficult, I will try to do all my best to get good job in my field of specialization. But I have one fear; corruption is common in getting job and you can get good job when you give significant amount of money. I cannot afford that. What is good for me is that, I live in urban area where I can get 
access to job vacancies and information."

But, most female with low and medium academic achievement who come from rural area expect any available job with moderate salary as far as it helps them to lead their life independently. Contrary to this, regardless of their residence, female fresh graduates with high academic achievement expect and prefer relatively better job of their profession with higher salary. They are confident that they can get job and be successful.

Only one female from rural area with very high distinction has responded differently as follows:

"Having such good academic achievement, it is normal to expect good job and prefer better salary. But what if not that is the case? I should not back to home and stay with my family while other jobs are available with lesser salary. I am ready to work any available job as far as it helps me to lead my life independently and support my families. That is much better than staying home, holding university degree."

In general, all participants with high and very high academic distinction have more or less similar job expectation and preference regardless of their sex and residence. Students with high academic achievement have negative attitude toward self-employment, expecting job from government. One participant during the interview stated verbatim:

"How can my parents and neighbors perceive me when I engaged in tasks like cobblestone works, and shoes shading? Such jobs do not want specialization. Therefore, how can I involve in such jobs, spending much amount of time and money in education? To avoid such bad impression of the society, I prefer to wait till I get recruited in governmental or non-governmental organizations at any expense".

However, most participants with average academic achievement do not bother about their qualification and field of specialization. E.g. one participant explained during the focus group discussion verbatim in Amharic language

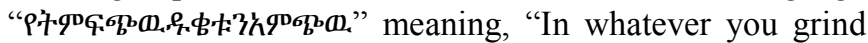
bring the powder!"

In general, when asked what type of job they expect and prefer to work, majority $(62.5 \%)$ of fresh graduates with relatively lower academic achievement answered that:

"They do not expect to get job in their profession. They think that, the numbers of graduates are very high compared to the existing employment opportunity. Hence the competition will be very high that and I think that only students with high grade will be employed."

Considering themselves as inadequate and incompetent, fresh graduates with low academic achievement belief that, they will not be employed. As a result, they have a desire to start small business like, trade, cafeteria and breading animals without their field of specialization. Due to their low grade and feeling of incompetency, fresh graduates with low academic achievement prefer to start own job E.g. two participants during the focus group discussion explained that:

"They need to compensate their academic limitations through hard-working of their personal businesses. They are sure that they will generate income more than their friends who have good academic achievement and those who will be recruited in different governmental or nongovernmental organizations in the near future".

\subsection{Job Expectation and Preference in Relation to Fresh Graduates' Residence}

Fresh graduates' residence is another variable that has its own impact on graduates' job expectation and preference. In this study, regardless of their academic achievement and residence, most male graduates expect to be employed with their field and prefer to have highest salary compared to others. The reason is that, there are different employing organizations that create job opportunity; as one participant among them stated that:

"Who knows, one day I will be employed in my filed of specialization. To be honest, I will never give up...! "Never say Never" said Justin Biber in his famous song. I may start working my own job for time, just not to be return back to my family holding degree, but I will continue to strive to be employed. I will search for job of my profession",

On the other hand, regardless of their academic achievement, majority of female fresh graduates from rural area expect that, it is difficult for them to be employed. They prefer to start local jobs which can offer them moderate salary, than go away from their family to search job.

But, one female fresh graduate from rural are with high academic achievement beliefs that her residences can affect her but could not prevent her from being employed; stating that:

"I know many challenges are there but they all are not more challenging than my three year campus life. Life teaches me a lot.... I can overcome all the difficulties and achieve my goal. I am a psychologist, I will try to change challenges into opportunities."

However, female fresh graduates who are from rural area and with low academic distinction do not prefer to engage in tasks like farming and animal breading. Instead, they prefer to engage in jobs like trade and other related jobs such as migrating to the nearby urban area. This is because, they consider themselves as incapable of working in farming and animal breading like their male counter parts. This could also be related to the gender role as per their community:

"In some rural area of Ethiopia, farming, animal breading and other outside work is left for male, whereas in-home works are reserved for females. For example; even though there is an exception from culture to culture, and place to place...etc., is not common for male to prepare food in home. It is even considered as shame; male acting like female. Similarly, there are jobs that are totally for male, and when done by female considered inappropriate"

Moreover, fresh graduates with low academic distinction, who are living in urban are prefer to start small scale trade and industries by creating business partnership.

"They do not bother about working by their specialization. 
The only concern of the participants was to possess anything that can generate income and they need to lead their life independently, as backing to family after graduation is considered failure or inability to lead their life".

Generally, fresh graduates with high and very high academic achievement expected and preferred to be employed regardless of their sex and residence. But, job expectation and preference of fresh graduates with low academic distinction depends on their residence and sex, showing that, sex and residence affect job expectation and preference of Psychology fresh graduates with low academic distinction.

\section{Conclusions}

Based on the results of the study, the following conclusions were made:

Except some variation as a result of sex, residence and academic achievement, majority of psychology fresh graduates expect and prefer to be employed with good salary in different organizations by their field of specialization. There is gender difference in job expectation and preference among psychology fresh graduates. That is, male and female psychology fresh graduates have different job expectation and preference. Their academic achievement and residence remain constant; Psychology fresh male graduates in general expect and prefer good jobs with higher salary. On the other hand, female psychology fresh graduates expect and prefer relatively simple job with lower salary.

With the exception due to sex and residence, mainly job expectation and preference of both male and female fresh graduates are affected by their academic achievement. Majority of psychology fresh graduates with high and very high academic achievement expect and prefer good job in their field of specialization with relatively high salary. Fresh psychology graduates' job expectation and preference is also affected by their residence. Regardless of their academic achievement and residence, majority of male psychology fresh graduates expect and prefer to be employed with highest salary. But, regardless of their academic achievement, most female psychology fresh graduates, from rural area beliefs that they could not be employed, so expect and prefer to start local and small business.

\section{Recommendations}

Based on the findings and conclusions, the following recommendations are forwarded:

a. Most psychology fresh graduates expect and prefer to be employed in their field of specialization. Hence, Ethiopian Minster of Education and Mekelle University shall work together on creating linkage and job opportunities where psychology graduates can be employed and serve their community by their profession.

b. There is gender difference among fresh psychology graduates regarding their job expectation and preference. Majority of female fresh graduates undervalue their potential, ability and interest. Therefore, Mekelle University and psychology department shall prepare life skills training for female psychology fresh graduates prior to their graduation.

c. Regardless of their sex and academic achievement, fresh psychology graduates' job expectation and preference are found to be affected by their residence. So, Ethiopian Minister of Education shall create means in which all fresh graduates get equal access to job chances such as accessibility of job vacancies on mobile internet and Radio in rural area.

d. Regardless of their sex, some fresh psychology graduates with medium and low academic achievement have wrong expectation and preference about their future job. They consider themselves as unfit and incompetent to be employed. Hence, Mekelle University in collaboration with Psychology department shall provide life skills training for fresh psychology graduates with medium and low academic achievement.

\section{References}

[1] ILO (2010). Growth- employment- poverty reduction linkages: A framework for recovery and accelerated progress towards the Millennium Development Goals: Economic Report on Africa 2010.

[2] Adebayo, A. (1999): Youth Unemployment and National Directorate of Employment and self-employment programs: Nigerian Journal of Economics and Social Studies; Vol. 41 (1).

[3] Guarcell, L. and Rosita, F. (2009). Child labor and youth employment in Ethiopia: Youth employment and urban renewal youth employment habitat. World Bank: Washington.

[4] Brunero M, (2008). Youth Employment Problems in SubSaharan Africa; The case of South Africa: University of Toronto.

[5] Hanover Research, (2012). High Expectations And Student Success Prepared For Springfield R-Xii Public Schools: District Administration Practice.

[6] Jamal A. and Lim H. (2014). The effectiveness of finishing school programs from the perspectives of graduates and employers: Malaysian Journal of learning and instruction; Vol. 11:147-170.

[7] Tutorials Point., (2015). Job Search Skills help to go ahead. Tutorial point: Simply easy learning.

[8] Valli C., and Gianni, R, (2013). Serving the Labor Market: Job Search Skills for the Young People: International Labor Office.

[9] MIT, (2009). Job Search Guide: Staffing Services, MIT Human Resources Department, 2009.

[10] Azami Zaharim., et, Al, (2010). Employers' Perceptions and Expectation toward Engineering Graduates: A Study Case. ISSN: 1790-2769. 
[11] Daniel L., Tortoricey (2011). Unemployment Expectations and the Business Cycle.

[12] Yunuen Rangel, Jesus E. Peinado, Ramon Lugo, and Francisco J. Flores, (2016). Factorial Composition of the Selfefficacy in the Socio-cultural Sphere Scale in College Freshmen: Psychology and Behavioral Sciences. Vol. 5, No. 1, 2016, pp. 1-6. doi: 10.11648/j.pbs.20160501.11.

[13] CSA. (2005). The National Labor Force Survey Central Statistics Agency. Addis Ababa: Ethiopia.

[14] Lynne, M and Diane H. (2008). Young people's Job Expectations and preferences. University of Surrey: Guildford.

[15] British Council, (2014). Can higher education solve Africa's job crisis? Understanding graduate employability in SubSaharan Africa: www.britishcouncil.org/education/ihe

[16] Ume-Amen (2014). Employers' Expectations versus Performance of Fresh Graduates: Business School. Vol, Xi, No.2.

[17] Melaku, W. (2008). Higher Education Quality Audit in Ethiopia: Analyzing the methods and procedures: Institute for Educational Research: University of Oslo.

[18] Leslie M. (2000). Women and men: Morality \& Ethics. Business horizon: Journal of Business ethics.
[19] Trond, P. and Vermond S. (2006). Are females worker less productive than male workers? Institute for Research on labor and employment: University of Berkley: California.

[20] C.S.A. (2005). Report on Labor Force Survey 1999 (Statistical Bulletin), Addis Ababa, Ethiopia.

[21] MoE (2002). The Education and Training Policy and its Implementation. Policy report Ministry of Education, Addis Ababa, Ethiopia.

[22] Aklilu, A. and Teshome N. (2011). Job Search and graduates employment in Ethiopia: Implications for Program Employment: Addis Ababa University.

[23] Hanan Ebrahim Abd El Aziz Rady, Lamiaa Ahmed El-Sayed, (2015) Psychosocial and Educational Problems for Undergraduate University Nursing Students: Psychology and Behavioral Sciences. Vol. 4, No. 3, 2015, pp. 116-124. doi: 10.11648/j.pbs.20150403.15

[24] Bruce L. Berg. (2001). Qualitative Research Methods for Social Sciences ( $4^{\text {th }}$ edition). California State University: Long Beach.

[25] Klaus, B and Nicholas M. (2002). A hand Book of Qualitative methodologies for Mass Communication Research: London and New York: Taylor and Francis e-library. 